\title{
Coronavirus Disease 2019 as a challenge for maritime medicine
}

\author{
Katarzyna Sikorska \\ Department of Tropical and Parasitic Diseases, Institute of Maritime and Tropical Medicine, Faculty of Health \\ Sciences with Institute of Maritime and Tropical Medicine, Medical University of Gdansk, Gdynia, Poland
}

On 11 March 2020 World Health Organization (WHO) "made the assessment that Coronavirus Disease 2019 (COVID-19) can be characterised as a pandemic". Six weeks earlier, on 30 January 2020, the outbreak caused by a novel coronavirus was declared a Public Health Emergency of International Concern [1].

The history of this new threat to human population is very short with rapid evolution in his perception and unprecedented decisions to limit global communication that have never been seen before in the era of technical civilisation.

The first cases of pneumonia of unknown origin which was linked to a seafood and wet animal wholesale market in Wuhan, China were reported on 31 December 2019 [2]. In mid-March 2020 there are 133,860 cases worldwide in 122 countries with 4967 deaths in all continents excluding Antarctica. The rate of increase in the number of new cases and deaths outside of China does not decrease [3]. The lack of both: effective antiviral therapy and the possibility of active immunisation (vaccine) means that the basic tool to fight the epidemic is an old weapon, which was used in the past against highly contagious infectious diseases: quarantine and isolation. Fortunately, now it is enhanced by the possibility of early, effective detection of infection using methods of molecular biology.

On 12 February 2020 a new strain of zoonotic coronavirus which has not been previously identified in humans was named severe acute respiratory syndrome coronavirus 2 (SARS-CoV-2). COVID-19 is a name of a new disease associated with this virus. Human-to-human transmission via respiratory droplet or direct contact with infected subjects was confirmed and also a clinical picture from mild disease of respiratory tract to severe pneumonia and life threatening respiratory failure has been extensively described. Mean mortality is estimated to be $\sim 3.5 \%$ with rapid increase in older patients reaching $15 \%$ in the group of $>80$ years and with underlying medical conditions [4]. Still many issues on persistence of contagiousness, type and efficacy of im- mune response, risk of reinfections are not fully explained, becoming a scientific challenge.

At present SARS-CoV-2, due to its dynamic spread all over the world, appears to be a significant threat to public health in all spaces, especially in international transport, including maritime conveyance. The problem of dealing with a suspected case of COVID-19 does not bypass board ships, not only cruise ships. Dramatic fate of tourists imprisoned on luxury cruise ships because of spread of SARS-CoV-2 infection on board was an unexpected and shocking consequence of rapid, inauspicious changes of epidemiological situation on mainland. It has highlighted the need to train personnel working at sea in area of epidemiology, understanding of psychosocial conditions of epidemic and the basic principles of infectious disease prevention. It turned out necessary to prepare documents organising the rules of conduct in the event of a new epidemic threat on board ship. Early detection, prevention, and control of COVID-19 on ships appeared to be important tasks both to protect the sea workers' and travellers' health and to avoid transmission of the virus by disembarking passengers and crew members who are suspected of having COVID-19 $[5,6]$.

\section{REFERENCES}

1. www.who.int/emergencies/diseases/novel-coronavirus-2019 (access: 13 March 2020).

2. Zhu Na, Zhang D, Wang W, et al. China Novel Coronavirus Investigating and Research Team. A Novel Coronavirus from Patients with Pneumonia in China, 2019. N Engl J Med. 2020; 382(8): 727-733, doi: 10.1056/NEJMoa2001017, indexed in Pubmed: 31978945.

3. www.ecdc.europa.eu/en/novel-coronavirus (access: 13 March 2020).

4. Guan WJ, Ni ZY, Hu Yu, et al. China Medical Treatment Expert Group for Covid-19. Clinical Characteristics of Coronavirus Disease 2019 in China. N Engl J Med. 2020 [Epub ahead of print], doi: 10.1056/ NEJMoa2002032, indexed in Pubmed: 32109013.

5. Operational consideration for managing COVID-19 cases and outbreaks on board ships. Interim guidance February 2020. World Health Organisation/date of access: 13 March 2020.

6. www.cdc.gov/quarantine/maritime/recommendations-for-ships (access: 13 March 2020). 